\title{
A Novel Technique for the Assessment of Preoperative Cardiovascular Risk: Reactive Hyperemic Response to Short-Term Exercise
}

\author{
Robert Schier, ${ }^{1}$ Jochen Hinkelbein, ${ }^{1}$ Hanke Marcus, ${ }^{1}$ Ashley Smallwood, ${ }^{2}$ \\ Arlene M. Correa, ${ }^{3}$ Reza Mehran, ${ }^{3}$ Randa El-Zein, ${ }^{4}$ and Bernhard Riedel ${ }^{5}$ \\ ${ }^{1}$ Department of Anaesthesiology and Intensive Care Medicine, University Hospital of Cologne, Kerpener Strasse 62, \\ 50937 Cologne, Germany \\ ${ }^{2}$ Department of Anesthesiology and Pain Medicine, The University of Texas M. D. Anderson Cancer Center, \\ 1515 Holcombe Boulevard, Houston, TX 77030, USA \\ ${ }^{3}$ Department of Thoracic Surgery, The University of Texas M. D. Anderson Cancer Center, 1515 Holcombe Boulevard, \\ Houston, TX 77030, USA \\ ${ }^{4}$ Department of Epidemiology, The University of Texas M. D. Anderson Cancer Center, 1515 Holcombe Boulevard, \\ Houston, TX 77030, USA \\ ${ }^{5}$ Department of Anaesthesia and Pain Medicine, Peter MacCallum Cancer Centre and The University of Melbourne, \\ Locked Bag 1, A'Beckett Street, Melbourne, VIC 8006, Australia
}

Correspondence should be addressed to Robert Schier; robert.schier@gmx.net

Received 24 September 2012; Accepted 13 March 2013

Academic Editor: Joseph Fomusi Ndisang

Copyright (C) 2013 Robert Schier et al. This is an open access article distributed under the Creative Commons Attribution License, which permits unrestricted use, distribution, and reproduction in any medium, provided the original work is properly cited.

\begin{abstract}
Background. Perioperative vascular function has been widely studied using noninvasive techniques that measure reactive hyperemia as a surrogate marker of vascular function. However, studies are limited to a static setting with patients tested at rest. We hypothesized that exercise would increase reactive hyperemia as measured by digital thermal monitoring (DTM) in association to patients' cardiometabolic risk. Methods. Thirty patients ( $58 \pm 9$ years) scheduled for noncardiac surgery were studied prospectively. Preoperatively, temperature rebound (TR) following upper arm cuff occlusion was measured before and 10 minutes after exercise. Data are presented as means \pm SD. Statistical analysis utilized ANOVA and Fisher's exact test, with $P$ values $<0.05$ regarded as significant. Results. Following exercise, TR-derived parameters increased significantly (absolute: $0.53 \pm 0.95$ versus $0.04 \pm 0.42^{\circ} \mathrm{C}$, $P=0.04$, and $\%$ change: $1.78 \pm 3.29$ versus $0.14 \pm 1.27 \%, P=0.03)$. All patients with preoperative cardiac risk factors had a change in TR (after/before exercise, $\Delta \mathrm{TR}$ ) with values falling in the lower two tertiles of the study population $(\Delta \mathrm{TR}<1.1 \%)$. Conclusion. Exercise increased the reactive hyperemic response to ischemia. This dynamic response was blunted in patients with cardiac risk factors. The usability of this short-term effect for the preoperative assessment of endothelial function warrants further study.
\end{abstract}

\section{Introduction}

The physiological response of peripheral vasodilation during and shortly after exercise is affected by several factors. The vascular endothelium plays a central role in the regulation of vascular tone via nitric oxide, which has a key role in endothelial function, and is involved in exercise-induced vasodilation $[1,2]$. Impaired endothelial function is promoted by injury from mechanical forces and processes related to cardiovascular risk factors including ageing [3], hypertension [4], dyslipidaemia [5], impaired fasting glucose [6,7], insulin resistance [8], hyperhomocysteinemia [9], smoking [10, 11], or acute postprandial hypertriglyceridemia [12]. With an increasing incidence of these risk factors among the patient population presenting preoperatively, noninvasive assessment of endothelial-dependent vascular function in response to exercise might be a diagnostic tool gaining importance in the preoperative risk assessment. 
Despite advances in perioperative care, patients undergoing major noncardiac surgery continue to experience a high incidence of postoperative morbidity (15-36\%) and mortality (4.8-10.9\%, e.g., following pneumonectomy), with increased health care expenditure $[13,14]$. Cardiovascular risk factors predispose to perioperative morbidity and mortality, with evidence that patients with microvascular dysfunction undergoing cardiovascular interventions are at increased risk for postoperative complications $[15,16]$.

Given that the noncardiovascular surgical population increasingly presents with multiple cardiovascular risk factors [17], there is need to explore the role of endothelial dysfunction in this population from a clinical point of view. Recent studies investigating DTM have shown that impaired vascular reactivity correlated with the extent of myocardial perfusion defect and was found in patients with coronary artery disease, metabolic syndrome, and diabetes mellitus $[18,19]$. It is increasingly recognized as a diagnostic tool for cardiovascular risk assessment [20-22].

The noninvasive assessment of reactive hyperemia in response to exercise, as a surrogate marker of endothelialdependent vascular function, has not been described in the literature at this point. Therefore, we tested the hypothesis that acute exercise would increase reactive hyperemia regardless of changes in blood pressure, heart rate, and body temperature (primary endpoint). In addition, we tested the hypothesis that a lack of reactive hyperemia increase after exercise would correlate with preoperative cardiovascular risk factors (secondary endpoint).

\section{Methods}

2.1. Subjects. Following IRB approval (The University of Texas M.D. Anderson Cancer Center, study protocol no. 2003-0434), thirty consecutive patients scheduled for major noncardiac surgery (esophagectomy or major lung surgery, e.g., lobectomy or pneumonectomy) were prospectively enrolled into this observational trial. Exclusion criteria were any condition that deemed a patient unsatisfactory for surgery after the preanesthetic evaluation. Patients were evaluated with standard preoperative risk scores, including the American Society of Anesthesiologists (ASA) Physical Status Classification System and modified Lee Cardiac Risk Index $[23,24]$.

2.2. Study Endpoints. The primary endpoint of this pilot study investigated whether acute exercise would increase reactive hyperemia, a surrogate marker of vascular function, and that this effect would be blunted in the presence of preoperative cardiovascular risk factors (i.e., coronary artery disease, hypertension, diabetes, and obesity).

2.3. Measurement of Reactive Hyperemia. To ensure consistency, all measurements of reactive hyperemia were performed within one week of scheduled surgery. Measurements were performed before and 10 minutes after exercise in a quiet dimmed room at a controlled ambient temperature (20$25^{\circ} \mathrm{C}$ ) using a VENDYS 5000BC Digital Thermal Monitoring (DTM) system (Endothelix, Inc., Houston, TX, USA).
This FDA approved device consists of a computer-based thermometry system $\left(0.006^{\circ} \mathrm{C}\right.$ thermal resolution), with two special thermocouple fingertip probes designed to minimize the area of skin-probe contact and fingertip pressure. A standard sphygmomanometer cuff and a compressor unit to control cuff inflation and deflation is included to facilitate the occlusion-hyperemia protocol. The test is conducted with the patient at rest for 30 minutes in the supine position, in a quiet, dimmed room with ambient temperature of $24^{\circ} \mathrm{C}$ to $26^{\circ} \mathrm{C}$. VENDYS DTM probes are affixed to the index finger of each hand and after a period of stabilization of basal skin temperature (defined as stabilization within a $0.05^{\circ} \mathrm{C}$ threshold) the temperature is measured in the index fingers of both hands (of which the right arm only is subjected to occlusionhyperemia) with an automated, operator-independent protocol. The right upper arm cuff is rapidly inflated to $\geq 50 \mathrm{mmHg}$ above systolic pressure for 2 minutes and then rapidly deflated to invoke reactive hyperemia distally. Thermal tracings are measured continuously and digitized automatically using a computer-based thermometry system with $0.006^{\circ} \mathrm{C}$ thermal resolution. Dual channel temperature data is simultaneously acquired at a $1 \mathrm{~Hz}$ sample rate. Figure 1 shows a representative example of a temperature-time trace and the primary DTMderived measures, related to thermal debt and recovery that were recorded and calculated.

\section{Cardiopulmonary Exercise Testing (CPET)}

Prior to exercise, baseline vitals (heart rate, blood pressure, pulse oximetry, and ECG) and static pulmonary function tests (forced expiratory volume at 1 second, forced vital capacity, and maximal voluntary ventilation) were recorded for all patients. CPET was then performed as a multistage incremental "ramp workload" study using a cycle ergometer and a metabolic cart with standardized exercise software (Medgraphic Cardio-2CP system, Medical Graphics Corporation, St. Paul, MN, USA) for breath-by-breath analysis of gas exchange.

An initial acclimation period consisted of breath-bybreath gas exchange analysis performed in the supine, resting position for five minutes. After acclimation the patient pedaled at $60 \mathrm{rpm}$ with minimal resistance for three minutes (unloaded work). After three minutes, loaded work (increasing pedal resistance, watts per minute) followed a standardized ramp protocol to maximal symptom limited exertion that typically lasted 9-12 minutes. Exercise was terminated by the study patient or by the study investigator if symptoms of cardiovascular, pulmonary distress, and/or fatigue were observed. To ensure consistency, exercise above the anerobic threshold was required for inclusion into the study. Anerobic threshold (AT, $\mathrm{mL} / \mathrm{kg} / \mathrm{min}$ ) was defined as the $\mathrm{VO}_{2}$ at the inflection point as determined by the modified V-slope method of plotting carbon dioxide excretion $\left(\mathrm{VCO}_{2}\right)$ against oxygen uptake $\left(\mathrm{VO}_{2}\right)$ during increasing exercise intensity, as described by Wasserman et al. [25]. Gas exchange analysis recorded oxygen consumption $\left(\mathrm{VO}_{2}, \mathrm{~mL} / \mathrm{kg} / \mathrm{min}\right)$ and carbon dioxide production $\left(\mathrm{VCO}_{2}, \mathrm{~mL} / \mathrm{kg} / \mathrm{min}\right)$ at all phases of exercise. 


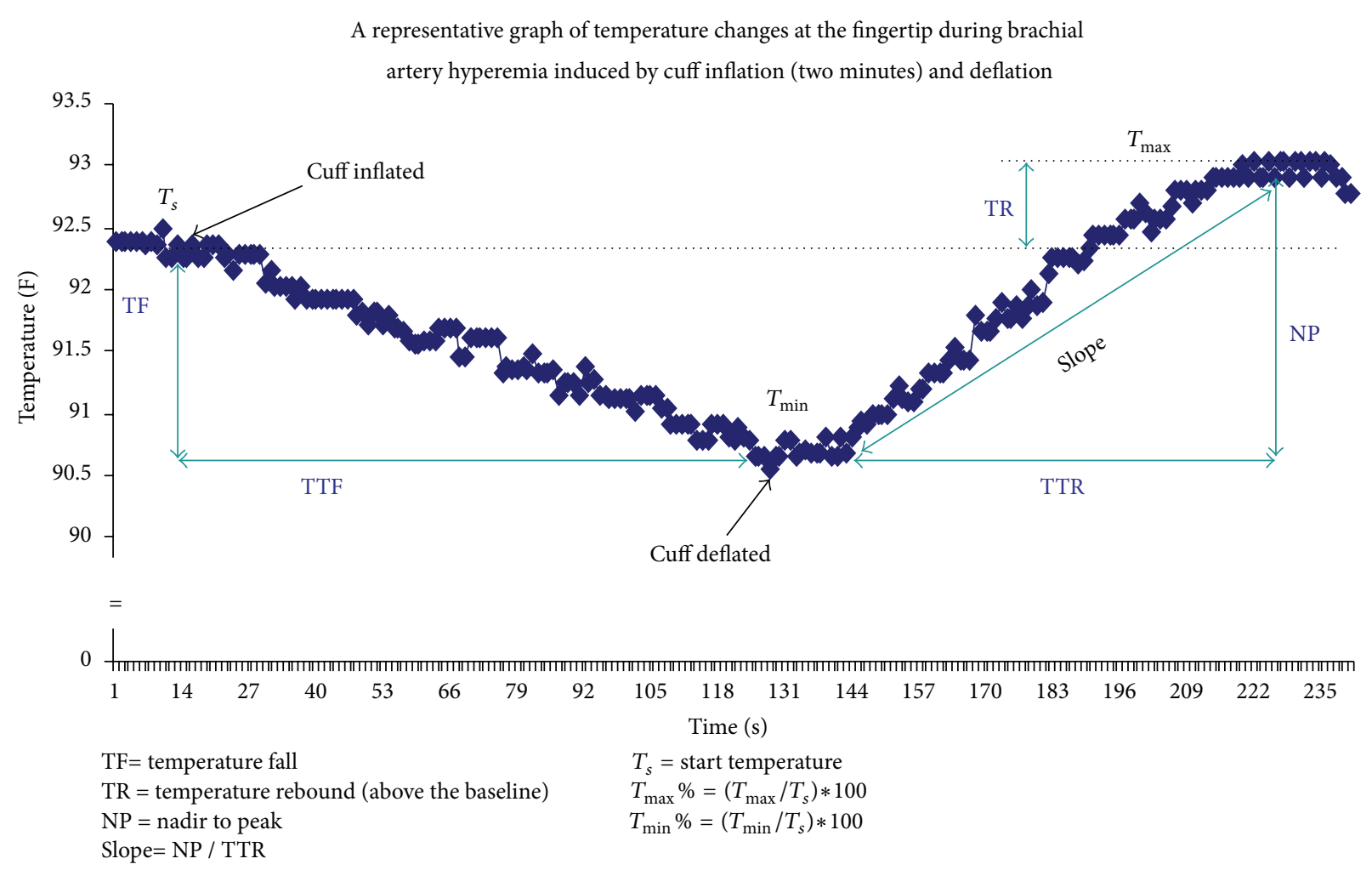

FIGURE 1: Representative example of a temperature-time trace in response to occlusion-hyperemia.

3.1. Statistical Analysis. The study sample size determination was based on data from a previous study by Harris et al. who enrolled nine patients to detect an increase of reactive hyperemia, as measured by flow-mediated dilation of the brachial artery, immediately after $45 \mathrm{~min}$ of exercise on a treadmill at $50 \%$ of their $\mathrm{VO}_{2}$ peak. We calculated that a sample of thirty patients would need to be enrolled to achieve $80 \%$ power to detect a log-linear trend in the primary endpoint assuming that the percentage increase of reactive hyperemia after exercise, as measured by TR, was 50 percentage points. Descriptive statistics were used to summarize the patients' demographic, clinical, and TR measures. The relative changes from baseline (before exercise) and after-exercise (10 minutes after peak exercise) were analyzed using repeated measures (ANOVA) and Wilcoxon signed ranks test.

Fisher's exact test was used to analyze for an association of perioperative variables -including patients' comorbidities (i.e., obesity, abdominal obesity, coronary artery disease, and Modified Lee Cardiac Risk Index) with TR measures when tertiles were used as cutoff points. A $P$ value of less than 0.05 was considered to indicate statistical significance. Statistical analyses were carried out using SAS 9.1 (SAS Institute, Cary, NC, USA) and S-Plus (version 8; Insightful Corp., Seattle, WA, USA).

\section{Results}

4.1. Clinical and Demographic Characteristics of the Study Participants. Thirty patients (18 males and 11 females) with mean age of $58 \pm 10$ years scheduled for major noncardiac surgery were enrolled in the study. Twenty-eight (93\%) patients had an increased perioperative risk with an ASA score $>2$; thirteen $(46 \%)$ patients had cardiovascular risk factors, for example, hypertension and dyslipidemia; and twenty-one $(70 \%)$ patients were current smokers. Table 1 summarizes the demographic and clinical characteristics of the study population.

4.2. Reactive Hyperemia (TR) before and after Exercise. Table 2 summarizes the vital signs (heart rate and blood pressure) and the reactive hyperemia measures before and after exercise. The heart rate was significantly increased $10 \mathrm{~min}$ after exercise when compared to baseline (mean: $75 \pm 10.58$ versus $\left.76 \pm 19.88 \mathrm{~min}^{-1} ; P=0.021\right)$. There were no differences in blood pressure before and after exercise. The starting temperature at the beginning of the reactive hyperemia measurement did not differ before and after exercise (mean: $32.84 \pm 1.78$ versus $\left.32.23 \pm 2.01^{\circ} \mathrm{C} ; P=0.147\right)$.

Reactive hyperemia was significantly increased $10 \mathrm{~min}$ after exercise with an absolute TR increase of $0.04 \pm 0.42$ versus $0.53 \pm 0.95^{\circ} \mathrm{C}, P=0.035$ and a relative TR increase of $0.14 \pm 1.27$ versus $1.78 \pm 3.29 \%, P=0.033$ (Figure 2 ). Area under the curve (AUC) of the TR slope was significantly lower after exercise with AUC $15 \mathrm{sec}$ : $14.89 \pm 4.70$ versus $11.92 \pm 5.26, P=0.019$; AUC 30 sec: $29.01 \pm 9.04$ versus $23.29 \pm 10.23, P=0.017$; AUC 45 sec: $41.50 \pm 12.86$ versus $33.34 \pm 14.53, P=0.017$; and AUC 60 sec: $52.11 \pm 16.15$ versus $41.85 \pm 18.12, P=0.020$. 
TABLE 1: Clinical characteristics.

\begin{tabular}{|c|c|c|c|}
\hline & $n$ & $\begin{array}{l}\text { Mean } \\
( \pm \text { SD })\end{array}$ & $\begin{array}{c}\text { Median } \\
\text { (range) }\end{array}$ \\
\hline Age, y & 30 & $58( \pm 9.93)$ & $59(45-70)$ \\
\hline Height, m & 30 & $1.70( \pm 0.11)$ & 1.70 \\
\hline Weight, kg & 30 & $83( \pm 18.62)$ & 81 \\
\hline Waist, $\mathrm{cm}$ & 28 & $104( \pm 38.48)$ & 98 \\
\hline BMI, $(\mathrm{kg} / \mathrm{m})^{2}$ & 30 & $28( \pm 4.76)$ & 28 \\
\hline PreOp hemoglobin, mg/dL & 30 & $13( \pm 1.16)$ & 13 \\
\hline PreOp fasting glucose, $\mathrm{mg} / \mathrm{dL}$ & 30 & $103( \pm 24.63)$ & 100 \\
\hline PreOp creatinine, mg/dL & 28 & $1.03( \pm 0.24)$ & 1.00 \\
\hline Length of hospital stay, d & 30 & $12( \pm 13.91)$ & 7 \\
\hline \multirow[t]{2}{*}{ Length of ICU stay, d } & 30 & $4( \pm 13.39)$ & 0 \\
\hline & $n(\%)$ & & \\
\hline Sex, female & $11(37)$ & & \\
\hline Obesity, $n(\%)$ & $10(33)$ & & \\
\hline Abdominal obesity, $n(\%)$ & $13(46)$ & & \\
\hline Smoker, $n(\%)$ & $21(70)$ & & \\
\hline $\begin{array}{l}\text { Coronary artery disease }{ }^{* *}, \\
n(\%)\end{array}$ & $1(3)$ & & \\
\hline Hypertension, $n(\%)$ & $13(43)$ & & \\
\hline Diabetes, $n(\%)$ & $4(13)$ & & \\
\hline Dyslipidemia, $n(\%)$ & $13(43)$ & & \\
\hline Statin therapy, $n(\%)$ & $5(17)$ & & \\
\hline$\beta$-Blocker therapy, $n(\%)$ & $6(20)$ & & \\
\hline ACE-inhibitor therapy, $n(\%)$ & $4(13)$ & & \\
\hline ASA risk score $>2, n(\%)$ & $28(93)$ & & \\
\hline $\begin{array}{l}\text { Lee Cardiac Risk Index }>2 \text {, } \\
n(\%)\end{array}$ & $3(10)$ & & \\
\hline Chemotherapy, $n$ (\%) & $13(43)$ & & \\
\hline Radiation therapy, $n$ (\%) & $10(33)$ & & \\
\hline
\end{tabular}

There was no association between clinical characteristics and low TR values (2 lower tertiles) when compared to high TR values (upper tertile) (Table 3 ).

\section{Discussion}

The principal finding of the present study is that a single episode of acute exercise above the anerobic threshold enhanced the reactive hyperemia, a surrogate marker of endothelial function. These results imply that a short period of exercise enhances cutaneous perfusion and is associated with an increase in the release and/or bioactivity of endogenous vasodilatative mediators (e.g., NO) in the endothelial cells of skin vasculature. We were able to measure this shortterm effect with the use of digital thermal monitoring (DTM) of temperature rebound (TR), which provides a noninvasive assessment of vascular function.

However, the diagnostic value of our findings in terms of preoperative assessment of endothelial dysfunction warrants further research. Although we found that patients with

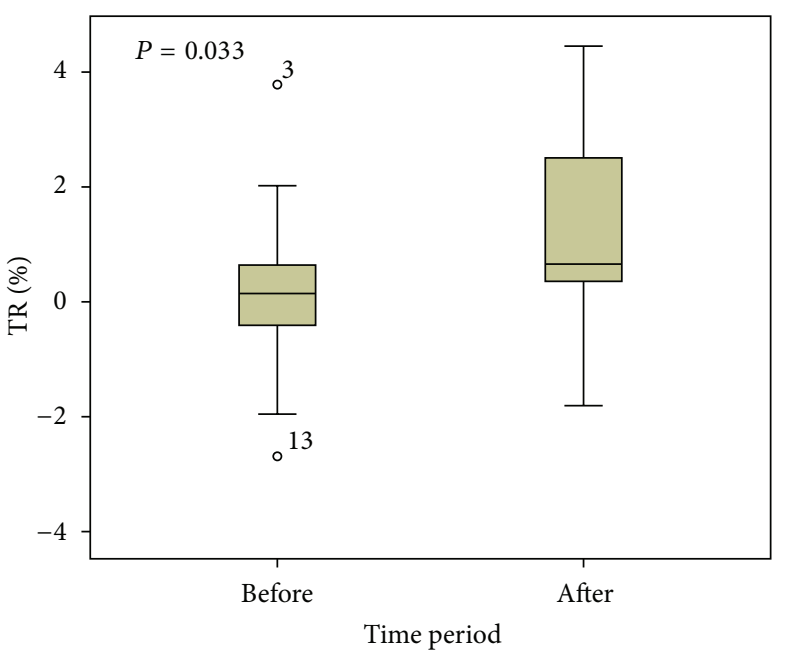

FIGURE 2: Increase of reactive hyperemia (temperature rebound, TR\%) 10 minutes after peak exercise.

preoperative cardiac risk factors and postoperative complications were within the lower 2 tertiles of the study population $(\Delta \mathrm{TR}<1.1 \%)$, this observation needs to be validated in a larger patient population.

In agreement with our findings, previous work has demonstrated that acute exercise increases skin blood flow and cutaneous vascular conductance accompanied by enhanced plasma NO metabolite levels and acetylcholine-induced cutaneous perfusion [26]. These authors suggested that endothelium-dependent dilation in skin vasculature is enhanced by moderate exercise training and reversed to the pretraining state with detraining.

Furthermore, our observations suggest that this effect can be reproduced by a single episode of exercise above the anerobic threshold increasing the aerobic capacity and vascular responsiveness to acute exercise.

In contrast, a previous study investigating on the effect of 6 months of aerobic exercise in patients with type 2 diabetes mellitus was not able to show an improvement of microvascular dysfunction [27]. The authors interpreted their negative results with the hypothesis that micro- and macrocirculation respond differently to the exercise stimulus. We were able to observe a significant increase of reactive hyperemia after a short exercise stimulus. However, it remains unclear how long this effect would have lasted on and we suggest that our observed physiological response to exercise has rather diagnostic than therapeutic value.

Our study has implications for preoperative assessment of endothelial function, as the observed increased reactive hyperemic signal shortly after exercise may serve as a diagnostic tool. Impairment of endothelial function is a precursor for cardiovascular disease and precedes the morphological changes associated with atherosclerosis in the blood vessels [28] and the clinical manifestations of its associated complications (e.g., myocardial infarction, stroke) [29, 30]. Furthermore, any transient inflammatory burden or a systemic inflammatory state also adversely affects endotheliumdependent vascular function with consequent increase in risk 
TABLE 2: Reactive hyperemia (TR) before and after exercise.

\begin{tabular}{|c|c|c|c|c|c|c|c|}
\hline & \multicolumn{3}{|c|}{ Before exercise } & \multicolumn{3}{|c|}{ After exercise (10 min after) } & \multirow{2}{*}{$P$ values } \\
\hline & $N$ & Mean & Std deviation & $N$ & Mean & Std deviation & \\
\hline Starting temperature $\left({ }^{\circ} \mathrm{C}\right)$ & 30 & 32.84 & 1.78 & 30 & 32.23 & 2.01 & 0.147 \\
\hline Temperature rebound $\left(\mathrm{TR}^{\circ} \mathrm{C}\right)$ & 30 & 0.04 & 0.42 & 30 & 0.53 & 0.95 & $0.035^{*}$ \\
\hline Temperature rebound (TR\%) & 30 & 0.14 & 1.27 & 30 & 1.78 & 3.29 & $0.033^{*}$ \\
\hline Area under curve after $15 \mathrm{sec}$ & 30 & 14.89 & 4.70 & 30 & 11.92 & 5.26 & $0.019^{*}$ \\
\hline Area under curve after $30 \mathrm{sec}$ & 30 & 29.01 & 9.04 & 30 & 23.29 & 10.23 & $0.017^{*}$ \\
\hline Area under curve after $45 \mathrm{sec}$ & 30 & 41.50 & 12.86 & 30 & 33.34 & 14.53 & $0.017^{*}$ \\
\hline Area under curve after $60 \mathrm{sec}$ & 30 & 52.11 & 16.15 & 30 & 41.85 & 18.12 & $0.020^{*}$ \\
\hline Heart rate (bpm) & 27 & 75 & 10.58 & 28 & 76 & 19.88 & 0.021 \\
\hline Systolic blood pressure ( $\mathrm{mmHg}$ ) & 27 & 128 & 16.94 & 28 & 132 & 16.35 & 0.216 \\
\hline Diastolic blood pressure $(\mathrm{mmHg})$ & 27 & 76 & 6.09 & 28 & 79 & 9.06 & 0.081 \\
\hline Mean blood pressure $(\mathrm{mmHg})$ & 27 & 94 & 11.59 & 28 & 98 & 2.01 & 0.094 \\
\hline
\end{tabular}

${ }^{*}$ Wilcoxon signed ranks test.

TABLE 3: Clinical characteristics and tertiles of TR \% change after exercise (pre-/postexercise difference).

\begin{tabular}{|c|c|c|c|c|}
\hline & $n$ & $\begin{array}{c}\text { Lower } 2 \text { tertiles } \\
(<-0.0952 \text { and }<1.1162)\end{array}$ & $\begin{array}{c}\text { Upper tertiles } \\
(\geq 1.1162)\end{array}$ & $P$ value* \\
\hline Age, $y$ & 30 & $57.5 \pm 11.3$ & $59.1 \pm 6.7$ & 0.685 \\
\hline Sex, $n(\%)$ female & 11 & $6(55)$ & $5(45)$ & 0.425 \\
\hline Height, m & 30 & $1.7 \pm 0.1$ & $1.7 \pm 0.1$ & 0.589 \\
\hline Weight, kg & 30 & $84.5 \pm 19.3$ & $79.5 \pm 17.8$ & 0.501 \\
\hline Waist, cm & 28 & $107.5 \pm 46.2$ & $95.9 \pm 10.1$ & 0.465 \\
\hline BMI, $(\mathrm{kg} / \mathrm{m})^{2}$ & 30 & $28.8 \pm 5.4$ & $27.7 \pm 3.3$ & 0.567 \\
\hline Obesity, $n(\%)$ & 10 & $8(80)$ & $2(20)$ & 0.419 \\
\hline Abdominal obesity, $n(\%)$ & 13 & $8(62)$ & $5(38)$ & 0.505 \\
\hline Smoker, $n(\%)$ & 21 & $12(57)$ & $9(43)$ & 0.204 \\
\hline Coronary artery disease $^{* *}, n(\%)$ & 1 & $1(100)$ & $0(0)$ & 1.000 \\
\hline Hypertension, $n(\%)$ & 13 & $11(85)$ & $2(15)$ & 0.119 \\
\hline Diabetes, $n(\%)$ & 4 & $4(100)$ & $0(0)$ & 0.272 \\
\hline Dyslipidemia, $n(\%)$ & 13 & $8(62)$ & $5(38)$ & 0.705 \\
\hline Statin therapy, $n(\%)$ & 5 & $3(60)$ & $2(40)$ & 1.000 \\
\hline$\beta$-Blocker therapy, $n(\%)$ & 6 & $6(100)$ & $0(0)$ & 0.074 \\
\hline Aspirin therapy, $n(\%)$ & 5 & $5(100)$ & $0(0)$ & 0.140 \\
\hline ACE-inhibitor therapy, $n(\%)$ & 4 & $3(75)$ & $1(25)$ & 1.000 \\
\hline ASA risk score $>2, n(\%)$ & 28 & $19(68)$ & $9(32)$ & 0.615 \\
\hline Lee Cardiac Risk Index > 2, $n(\%)$ & 3 & $3(100)$ & $0(0)$ & 0.107 \\
\hline Chemotherapy, $n$ (\%) & 13 & $7(54)$ & $6(46)$ & 0.255 \\
\hline Radiation therapy, $n$ (\%) & 10 & $7(70)$ & $3(30)$ & 0.101 \\
\hline PreOp echo/EF, \% & 17 & $61.4 \pm 3.8$ & $62.4 \pm 6.9$ & 0.709 \\
\hline PreOp hemoglobin, mg/dL & 30 & $13.3 \pm 1.0$ & $13.5 \pm 1.4$ & 0.705 \\
\hline PreOp fasting glucose, $\mathrm{mg} / \mathrm{dL}$ & 30 & $106.7 \pm 28.6$ & $95.8 \pm 12.0$ & 0.260 \\
\hline PreOp creatinine, mg/dL & 28 & $1.0 \pm 0.3$ & $1.0 \pm 0.2$ & 0.509 \\
\hline Length of hospital stay, d & 30 & $11.2 \pm 11.7$ & $12.6 \pm 18.32$ & 0.800 \\
\hline Length of ICU Stay, d & 30 & $2.4 \pm 9.0$ & $6.3 \pm 19.9$ & 0.462 \\
\hline
\end{tabular}

* Fisher's exact test.

** Patient status after myocardial infarction (with or without intervention). 
for cardiovascular complications [31, 32]. In the perioperative context, inflammatory mediator release associated with surgical trauma has been shown to impair vascular function and correlate with both the duration and extent of major surgery [31-35]. This effect may be additive to the underlying endothelial dysfunction that is inherent in certain surgical patients as a result of their preoperative comorbidity burden and thus plays a significant role in certain perioperative complications (e.g., perioperative myocardial infarction, poor wound healing, ALI, and sepsis) $[33,35]$.

\section{Conclusions}

Based on our results, we suggest that the preoperative assessment of endothelial function using reactive hyperemia in response to exercise gains clinical importance as a potential risk assessment tool in the prevention of perioperative complications and should be further studied in a larger patient population.

\section{Disclosure}

The meeting at which the work has been presented is American Society of Anesthesiologists (ASA) Meeting, October 21, 2008, Orlando, FL, USA.

\section{Conflict of Interests}

The authors declare no conflict of interests.

\section{Acknowledgment}

This study was supported by IARS Grant funding.

\section{References}

[1] A. J. Maxwell, E. Schauble, D. Bernstein, and J. P. Cooke, "Limb blood flow during exercise is dependent on nitric oxide," Circulation, vol. 98, no. 4, pp. 369-374, 1998.

[2] J. R. Vane, E. E. Anggard, and R. M. Botting, "Regulatory functions of the vascular endothelium," The New England Journal of Medicine, vol. 323, no. 1, pp. 27-36, 1990.

[3] D. S. Celermajer, K. E. Sorensen, D. J. Spiegelhalter, D. Georgakopoulos, J. Robinson, and J. E. Deanfield, "Aging is associated with endothelial dysfunction in healthy men years before the age-related decline in women," Journal of the American College of Cardiology, vol. 24, no. 2, pp. 471-476, 1994.

[4] J. A. Panza, A. A. Quyyumi, J. E. Brush, and S. E. Epstein, "Abnormal endothelium-dependent vascular relaxation in patients with essential hypertension," The New England Journal of Medicine, vol. 323, no. 1, pp. 22-27, 1990.

[5] P. J. Chowienczyk, G. F. Watts, J. R. Cockcroft, and J. M. Ritter, "Impaired endothelium-dependent vasodilation of forearm resistance vessels in hypercholesterolaemia," Lancet, vol. 340, no. 8833, pp. 1430-1432, 1992.

[6] H. Kawano, T. Motoyama, O. Hirashima et al., "Hyperglycemia rapidly suppresses flow-mediated endothelium-dependent vasodilation of brachial artery," Journal of the American College of Cardiology, vol. 34, no. 1, pp. 146-154, 1999.
[7] S. B. Williams, A. B. Goldfine, F. K. Timimi et al., "Acute hyperglycemia attenuates endothelium-dependent vasodilation in humans in vivo," Circulation, vol. 97, no. 17, pp. 1695-1701, 1998.

[8] G. Arcaro, A. Cretti, S. Balzano et al., "Insulin causes endothelial dysfunction in humans: sites and mechanisms," Circulation, vol. 105, no. 5, pp. 576-582, 2002.

[9] A. Tawakol, T. Omland, M. Gerhard, J. T. Wu, and M. A. Creager, "Hyperhomocyst(e)inemia is associated with impaired endothelium- dependent vasodilation in humans," Circulation, vol. 95, no. 5, pp. 1119-1121, 1997.

[10] D. S. Celermajer, M. R. Adams, P. Clarkson et al., "Passive smoking and impaired endothelium-dependent arterial dilatation in healthy young adults," The New England Journal of Medicine, vol. 334, no. 3, pp. 150-154, 1996.

[11] D. S. Celermajer, K. E. Sorensen, D. Georgakopoulos et al., "Cigarette smoking is associated with dose-related and potentially reversible impairment of endothelium-dependent dilation in healthy young adults," Circulation, vol. 88, no. 5, pp. 2149$2155,1993$.

[12] H. Gaenzer, W. Sturm, G. Neumayr et al., "Pronounced postprandial lipemia impairs endothelium-dependent dilation of the brachial artery in men," Cardiovascular Research, vol. 52, no. 3, pp. 509-516, 2001.

[13] P. Devereaux, "Association between postoperative troponin levels and 30-day mortality among patients undergoing noncardiac surgery (VISION Study)," The Journal of the American Medical Association, vol. 307, pp. 2295-2304, 2012.

[14] A. A. Vaporciyan, K. W. Merriman, F. Ece et al., "Incidence of major pulmonary morbidity after pneumonectomy: association with timing of smoking cessation," Annals of Thoracic Surgery, vol. 73, no. 2, pp. 420-426, 2002.

[15] M. Akcakoyun, R. Kargin, A. C. Tanalp et al., "Predictive value of noninvasively determined endothelial dysfunction for long-term cardiovascular events and restenosis in patients undergoing coronary stent implantation: A Prospective Study," Coronary Artery Disease, vol. 19, no. 5, pp. 337-343, 2008.

[16] A. L. Huang, A. E. Silver, E. Shvenke et al., "Predictive value of reactive hyperemia for cardiovascular events in patients with peripheral arterial disease undergoing vascular surgery," Arteriosclerosis, Thrombosis, and Vascular Biology, vol. 27, no. 10, pp. 2113-2119, 2007.

[17] P. Mathieu, "Abdominal obesity and the metabolic syndrome: a surgeon's perspective," The Canadian Journal of Cardiology, vol. 24, pp. 19D-23D, 2008.

[18] N. Ahmadi, F. Hajsadeghi, K. Gul et al., "Vascular function measured by fingertip thermal reactivity is impaired in patients with metabolic syndrome and diabetes mellitus," Journal of Clinical Hypertension, vol. 11, no. 11, pp. 678-684, 2009.

[19] N. Ahmadi, V. Nabavi, V. Nuguri et al., "Low fingertip temperature rebound measured by digital thermal monitoring strongly correlates with the presence and extent of coronary artery disease diagnosed by 64 -slice multi-detector computed tomography," International Journal of Cardiovascular Imaging, vol. 25, no. 7, pp. 725-738, 2009.

[20] N. Ahmadi, F. Hajsadeghi, K. Gul et al., "Relations between digital thermal monitoring of vascular function, the Framingham risk score, and coronary artery calcium score," Journal of Cardiovascular Computed Tomography, vol. 2, no. 6, pp. 382388, 2008.

[21] K. M. Gul, N. Ahmadi, Z. Wang et al., "Digital thermal monitoring of vascular function: a novel tool to improve cardiovascular 
risk assessment," Vascular Medicine, vol. 14, no. 2, pp. 143-148, 2009.

[22] E. E. Van Der Wall, J. D. Schuijf, J. J. Bax, J. W. Jukema, and M. J. Schalij, "Fingertip digital thermal monitoring: a fingerprint for cardiovascular disease?" International Journal of Cardiovascular Imaging, vol. 26, no. 2, pp. 249-252, 2010.

[23] R. D. Dripps, A. Lamont, and J. E. Eckenhoff, "The role of anesthesia in surgical mortality," The Journal of the American Medical Association, vol. 178, pp. 261-266, 1961.

[24] T. H. Lee, E. R. Marcantonio, C. M. Mangione et al., "Derivation and prospective validation of a simple index for prediction of cardiac risk of major noncardiac surgery," Circulation, vol. 100, no. 10, pp. 1043-1049, 1999.

[25] K. Wasserman, J. E. Hansen, D. V. Sue, and B. J. Whipp, Principles of Exercise Testing and Interpretation, Lea \& Febiger, Philadelphia, Pa, USA, 1987.

[26] J. S. Wang, "Effects of exercise training and detraining on cutaneous microvascular function in man: the regulatory role of endothelium-dependent dilation in skin vasculature," European Journal of Applied Physiology, vol. 93, no. 4, pp. 429-434, 2005.

[27] A. R. Middlebrooke, L. M. Elston, K. M. MacLeod et al., "Six months of aerobic exercise does not improve microvascular function in type 2 diabetes mellitus," Diabetologia, vol. 49, no. 10, pp. 2263-2271, 2006.

[28] T. Heitzer, T. Schlinzig, K. Krohn, T. Meinertz, and T. Münzel, "Endothelial dysfunction, oxidative stress, and risk of cardiovascular events in patients with coronary artery disease," Circulation, vol. 104, no. 22, pp. 2673-2678, 2001.

[29] R. Ross, "The pathogenesis of atherosclerosis: a perspective for the 1990s," Nature, vol. 362, no. 6423, pp. 801-809, 1993.

[30] S. W. Werns, J. A. Walton, H. H. Hsia, E. G. Nabel, M. L. Sanz, and B. Pitt, "Evidence of endothelial dysfunction in angiographically normal coronary arteries of patients with coronary artery disease," Circulation, vol. 79, no. 2, pp. 287-291, 1989.

[31] M. S. Tonetti, F. D’Aiuto, L. Nibali et al., "Treatment of periodontitis and endothelial function," The New England Journal of Medicine, vol. 356, pp. 911-920, 2007.

[32] P. Vallance, J. Collier, and K. Bhagat, "Infection, inflammation, and infarction: does acute endothelial dysfunction provide a link?” The Lancet, vol. 349, no. 9062, pp. 1391-1392, 1997.

[33] E. Burnham and M. Moss, "Progenitor cells in acute lung injury," Minerva Anestesiologica, vol. 72, no. 6, pp. 369-374, 2006.

[34] B. J. Hunt, K. M. Jurd, A. D. Blann, and G. Y. H. Lip, "Relation between endothelial-cell activation and infection, inflammation, and infarction," The Lancet, vol. 350, no. 9073, pp. 293-294, 1997.

[35] N. Rafat, C. Hanusch, P. T. Brinkkoetter et al., "Increased circulating endothelial progenitor cells in septic patients: correlation with survival," Critical Care Medicine, vol. 35, no. 7, pp. 16771684, 2007. 


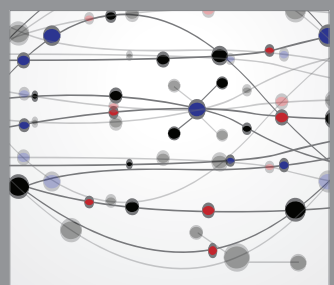

The Scientific World Journal
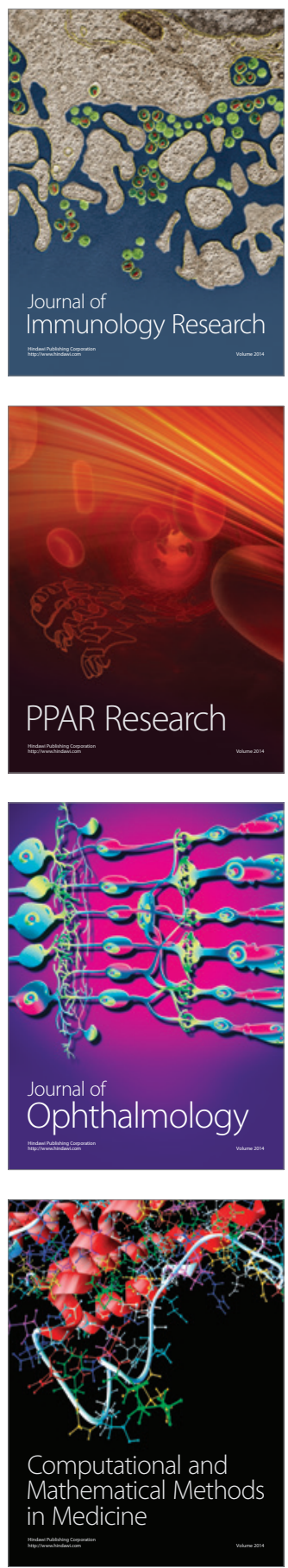

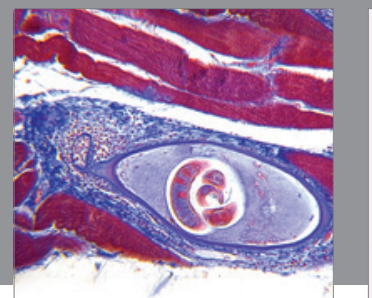

Gastroenterology

Research and Practice
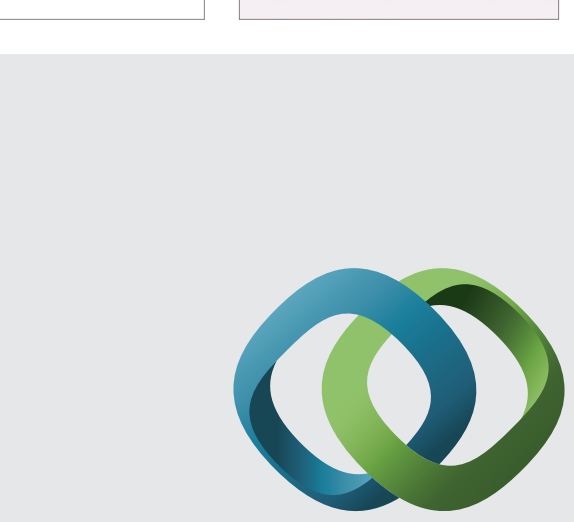

\section{Hindawi}

Submit your manuscripts at

http://www.hindawi.com
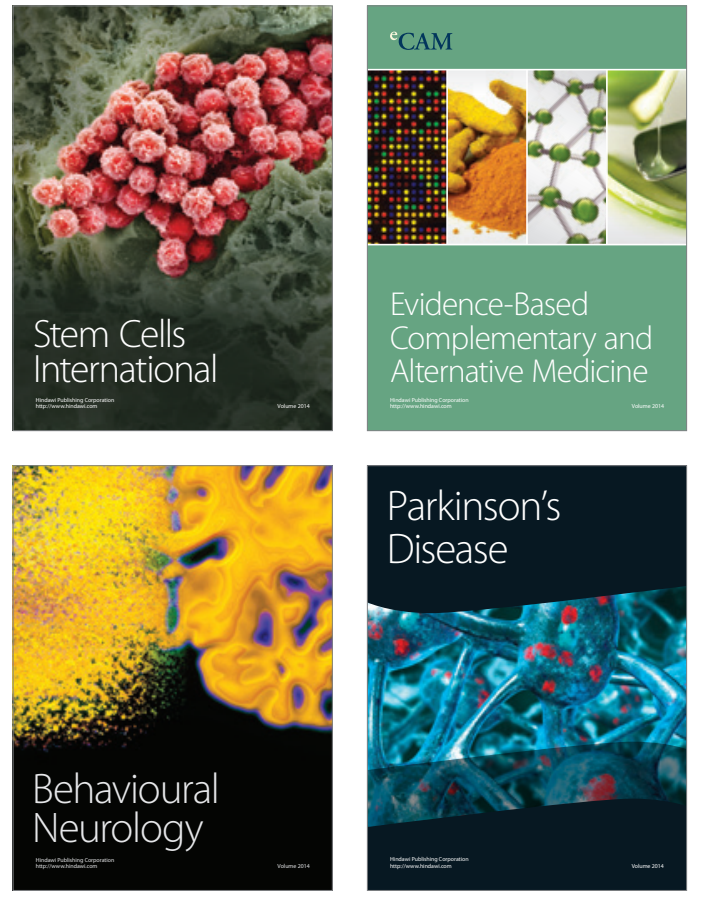
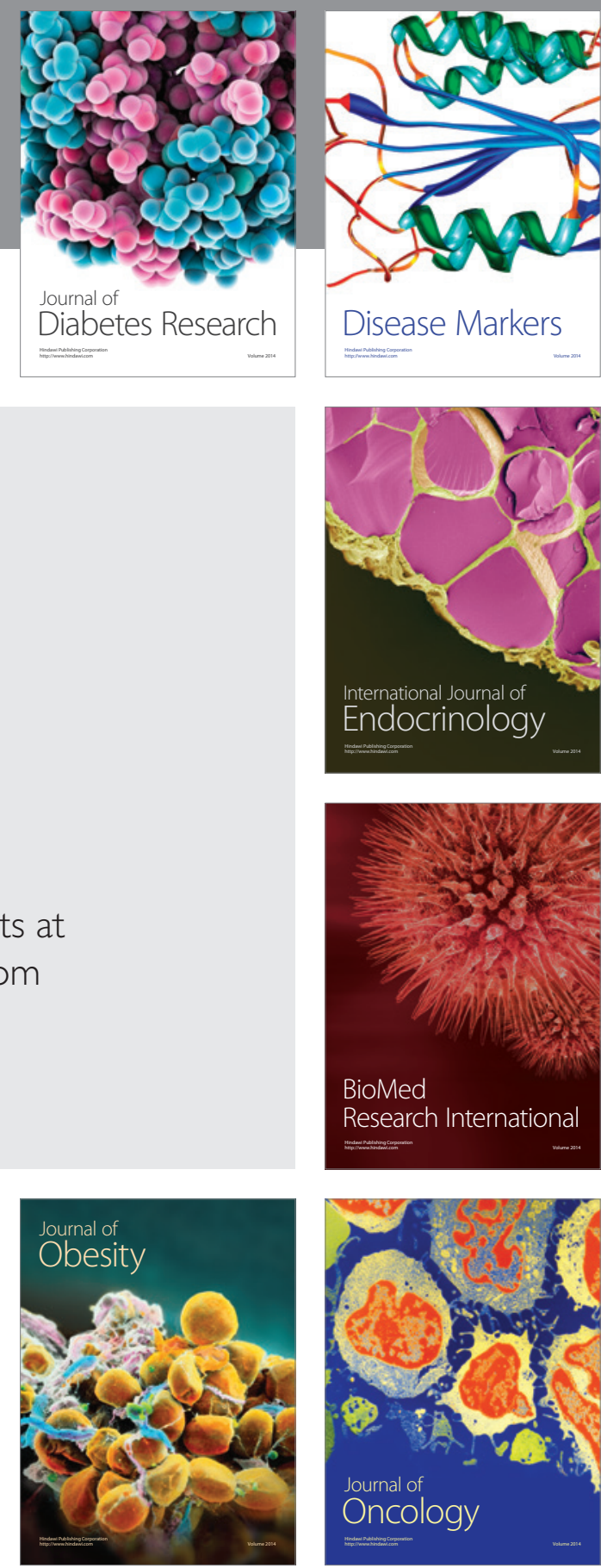

Disease Markers
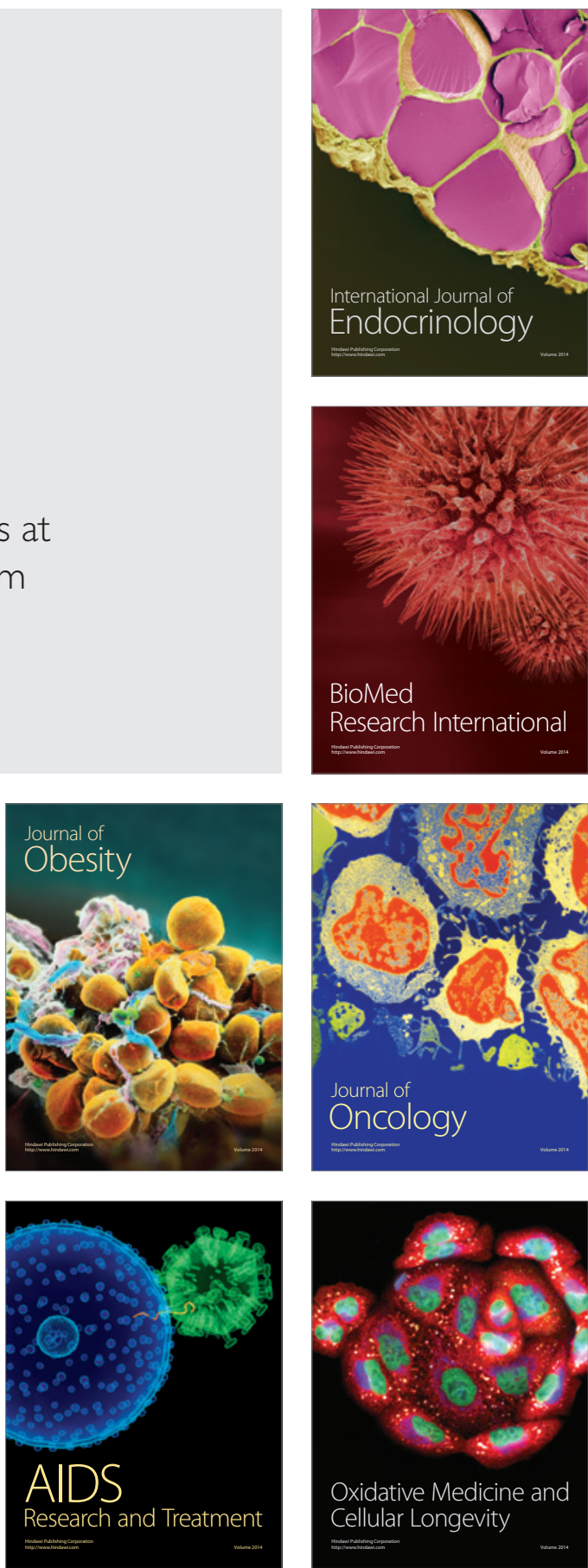